verschwindet jede Spur der Färbung vollständig. Bei erneutem Erhitzen tritt die besprochene Farbenänderung wieder ein. Nach den Versuchen von $\mathrm{R}$ eichard kann man die Reaktionsflüssigkeit wochenlang stehien lassen und trotzdem durch Erwärmen die Braunfärbung wieder hervorrufen.

4. A uf gerichtliche Chemie bezügliche Methoden.

Von

\title{
A. Czapski.
}

Arsen. Bei der Untersuchung von Friedhofserde auf Arsen hat sich G. Zuccàri ${ }^{1}$ ) zum qualitativen Nachweis der Gut$z$ eit'schen Probe und zur quantitativen Bestimmung des von Bressan in abgeänderten Verfahrens von Blattner und Brasseur ${ }^{2}$ ) bedient.

Nach des Verfassers Erfahrung ist es, um Irrtümer zu vermeiden, nötig, nicht nur die direkt den Sarg umgebende Erde, sondern auch solche aus grösserer Entfernung der Prüfung auf Arsen zu unterwerfen.

Zur Trennung des Arsens von Antimon und anderen Metallen haben Cantoni und $\mathrm{Chautems}{ }^{3}$ ) eine Methode angegeben, die ron $\mathrm{St}$. W. Collins ${ }^{4}$ ) nachgeprüft und verbessert wurde. Er fand, dass die Trennung vollkommener vor sich ging, wenn in der Weise gearbeitet wurde, dass man die Oxyde zunächst mit $30 \mathrm{ccm}$ Methylalkohol in das Destillationsgefäss überführte, ein Gemisch von 6 bis $15 \mathrm{ccm}$ konzentrierter Schwefelsäure und $20 \mathrm{ccm}$ Methylalkohol zufügte, 10 Minuten Salzsäuregas einleitete und destillierte. Nach zweimaliger Wiederholung der Destillation mit je $50 \mathrm{ccm}$ Methylalkohol ist die Trennung beendet, und das Arsen kann aus den vereinigten Destillaten mit Schwefelwasserstoff ausgefällt and in der üblichen Weise zur Bestimmung gebracht werden. Zwei Punkte müssen bei diesem Verfahren besonders beachtet werden. Zunächst muss das Untersuchungsmaterial vor dem Mischen mit Methylalkohol und Schwefelsäure vollkommen getrocknet werden, da bei Anwesenheit von Feuchtigkeit Antimon in das Destillat abergeht, und dann muss man besonders gereinigten Methylalkohol verwenden, da der Methylalkohol des Handels nicht geeignet ist.

1) Gazz. chim. ital. 42, II, 633; durch Chem. Zentralbl, 84, I, 958.(1913).

2) Vergl, diese Zeitschrift 52, 70 u. 376 (1913).

3) Vergl. diese Zeitschrift 49, 720 (1910) und 52, 314 (1913).

4) Analyst 37, 229 (1912); durch Zeitschrift f. Untersuchung der Nahrungsu. Genussmittel 25, 216 (1913). 